\title{
Investigating the impact of additive manufacturing data exchange standards for re-distributed manufacturing
}

\author{
Eujin Pei ${ }^{1}$ (D) Malte Ressin ${ }^{2} \cdot$ R. I. Campbell ${ }^{3} \cdot$ Benoit Eynard $^{4} \cdot$ Jinhua Xiao $^{4}$
}

Received: 10 December 2018 / Accepted: 20 May 2019 / Published online: 12 June 2019

(c) The Author(s) 2019

\begin{abstract}
The paradigm shift towards a decentralised approach of cloud manufacturing requires tighter standardisation and efficient interfaces between additive manufacturing (AM) data and production. In parallel with technology advancements, it is important to consider the digital chain of information. Although a plethora of AM formats exist, only some are commonly used for data transfer. None of these AM data transfer standards specifically addresses the needs of the re-distributed manufacturing (RDM) landscape. The purpose of this study is to identify the required features for AM data transfer standards to support a RDM landscape. The study examined the data flow from CAD to AM and reviewed established shortcomings of existing data exchange standards such as STL. After identifying the data exchange standards for AMF, 3MF, STEP and STEP-NC as promising replacements for STL, their premises, objectives, contributions and advantages were reviewed. The role of AM to support RDM by overcoming tooling costs and the associated need for economies of scale was also reviewed. Focus group interviews and surveys were conducted with AM and RDM experts from industry and academia and the participants' accounts were analysed for common themes and narratives. Finally, the suitability of existing data transfer formats was examined by compiling existing and expected standard features and having them rated by AM experts. The study showed that STEP-NC and AMF standards are ahead in implementing the most highly valued data transfer features. Open standards are also expected to further facilitate innovation in AM. The survey also identified that the top five features deemed most important by the participants for data exchange formats for RDM were regular internal structures/lattices, manufacturing tolerances, geometric representation, curvature representation, and surface structures. This study has contributed towards evaluating existing standards and their future development and adoption. It is hoped that the results will benefit policy makers and industry leaders to be aware of the importance of data exchange standards for AM so as to pave a clear roadmap for the Digital Economy in a RDM landscape.
\end{abstract}

Keywords Additive manufacturing $\cdot$ Standards $\cdot$ Data transfer $\cdot$ File formats $\cdot 3 \mathrm{D}$ printing

Eujin Pei

eujin.pei@brunel.ac.uk

Malte Ressin

malte.ressin@uwl.ac.uk

R. I. Campbell

R.I.Campbell@1boro.ac.uk

Benoit Eynard

benoit.eynard@utc.fr

Jinhua Xiao

jinhua.xiao@utc.fr
1 Brunel University London, Uxbridge UB8 3PH, UK

2 University of West London, London W5 5RF, UK

3 Loughborough University, Loughborough LE11 3TU, Leicestershire, UK

4 Université de Technologie de Compiègne (UTC), Compiègne, France 


\section{Introduction}

The impact of AM is far reaching and it has been suggested that it has the potential to alter the manufacturing landscape towards more sustainable, de-centralised and personalised means of production [1, 2]. In this work, the term Re-Distributed Manufacturing (RDM) is used to describe the rapidly changing geographies, organisational structures, value chains and distribution networks associated with advancements in material science, manufacturing capability and other ICT-based digital enabling technologies. Researchers claim an RDM landscape will result in a shift towards smaller-scale local manufacturing, caused by changes in transport and labour costs, the availability of materials and energy, the need for sustainability and access to information. Consequentially, this will drive new business models and value chains and change the dynamics of work and community with implications for industry and society. This research specifically aims to investigate the impact of AM data transfer standards for AM. The purpose is to understand what data exchange features are needed for standards to be effective in an RDM scenario. The Research Questions (RQ) are:

RQ1: What impact could AM data exchange standards have on an RDM landscape?

RQ2: Who are the users and beneficiaries of AM data exchange standards?

RQ3: What characteristics are needed to manage the AM data exchange standards for RDM?

RQ4: Which AM data transfer standard has the greatest competitive advantage for an RDM landscape?

RQ5: Are there opportunities for an open architecture AM data exchange standard?

\section{Literature review}

The literature review covers aspects of RDM and AM data exchange standards. The aim is to understand the features of AM and RDM, the data interface problems with current AM production methods, and how the choice of AM data exchange standards is influenced by practical scenarios and situations. The literature review also covers the process of data flow from CAD to AM and examines which standard is most widely used for data transfer. We also review existing data transfer standards in manufacturing, including their place in the design and manufacturing process and benchmark them according to the aims, advantages, drawbacks, similarities and dissimilarities among them. Although many AM formats exist, only some of them are used for data exchange of file information, manufacturing process and part geometry. The standards being investigated include
AMF, STEP, STEP-NC, STL and 3MF. STL is seen as the proprietary but de-facto standard in today's AM industry through frequent adoption by users and CAD software providers. STEP/STEP-NC will be a potential data standard for data exchange and sharing in AM, which defines the original design information, tolerance, and AM process [3]. STEP [4] documents protocols for product data representation and exchange in Part 242, which covers application protocols in managing model-based 3D engineering. STEP-NC [4] looks at physical device control, in particular for data models for computerised numerical controllers (NC) where Part 1 documents a general overview and the fundamental principles. AMF [5] is an XML-based format designed to allow CAD systems to describe the object geometry and with support for colour, materials, lattices, and constellations. The optional constellation element is used to define the position and arrangement of the parts within the file. Lastly, 3MF which is also an XML-based format was developed in parallel to the design of Windows Operating Systems with the goal of creating a seamless print control interface for consumers or manufacturers that would resolve interoperability issues. It must be noted that there are other formats such as.IGES,. NURBS,.OBJ, and.VRML which also provide varying degrees of capability, information, and accuracy for 3DP but will not be covered in this study as they are less popular and seldom used among manufacturers and AM end-users.

\subsection{Additive manufacturing (AM)}

The ISO/ASTM 52910:2018 Additive manufacturingdesign-requirements, guidelines and recommendations document categorises AM processes into (1) Binder Jetting, in which a liquid bonding agent is selectively deposited to join powder materials; (2) Directed Energy Deposition, in which focused thermal energy is used to fuse materials by melting as they are being deposited; (3) Material Extrusion, in which material is dispensed through a moving nozzle or orifice; (4) Material Jetting, in which droplets of build material are selectively deposited; (5) Powder Bed Fusion, in which thermal energy selectively fuses regions of a powder bed; (6) Sheet Lamination, in which sheets of material are bonded to form an object; and (7) Vat Photopolymerization, in which liquid photopolymer in a vat is selectively cured by light-activated polymerization. Compared to traditional manufacturing processes, such as milling, grinding, turning, EDM, etc., AM technology defines a process of adding the print material according to the layer-upon-layer accumulation.

However, it makes AM technology has a number of advantages [6]. It allows almost complete 3D control over artefact geometries and material properties, thus dramatically increasing the range of feasible products made without the need for tooling in directly print process. In many cases, 
it also produces less waste material. Manufacture of interlocking parts using AM eliminates the need for additional assembly processes and because it does not require specialist tooling for each part, AM also enables local, specialised and on-demand manufacturing. This means that parts can be produced at short notice, close to the location of consumption, and based on exact customer specifications. Since some raw materials are more easily procured in feeder or powder form, AM also simplifies supply chains by layering the required material [7]. As a result of these advantages, AM offers opportunities to extend conventional manufacturing methods as the integration of hybrid manufacturing, thus enabling the development of newer products, innovative business and information models, and flexible digital chains. For these reasons, AM has been referred to as the next industrial revolution (reference needed) although many practical barriers still exist. Commercial and industrial adoption of $\mathrm{AM}$ is challenged in several areas, such as quality control issues, artefact reliability, information interoperability, process repeatability, automatically data integration, etc.

\subsection{The additive manufacturing process}

In an AM process, an artefact is first created as a computeraided design (CAD) model that contains the geometry of the part before being produced using the specific AM methods. There are a number of stages and processes that need to be completed to realise this physical artefact. Several scholars have attempted to define key stages of the AM process. For example, Nassar and Reutzel [8] distinguish four stages. In the designing stage, a digital model of the artefact is created through the use of solid-modelling CAD software or by 3D Scanning an existing object and importing the data into the CAD environment. Next, in the process planning stage, the 3D model data is translated into a set of instructions for the operation of the AM machine. In the execution stage, the AM system creates the physical artefact in a layer-wise process. In the finishing stage, the support material is removed and the parts are dealt with according to the post-processing requirements, such as heat treatment. Finally, in the verification stage, the finished artefact is compared against the original CAD model for inspection and validation. The definition of the four stages are considered to be general and as a result, they have been deeply extended by Kim et al. [9] into further eight sub-stages linked by seven activities in Fig. 1.

While the specific stages described above cover most practices observed in the industry, some steps are argued by other researchers. For example, [10] proposed skipping the creation of a tessellated model, i.e. an approximate geometric description by discrete surfaces such as triangles. Instead, slicing, i.e. the generation of horizontal layers which combined form the physical model could be done directly from the CAD model with more calculations and handling. This would increase the precision of slices and unify the data sources for execution and verification [2]. For this paper, we propose a view of the AM process that combines those described by Nassar and Reutzel [8] and Kim et al. [9] as shown in Table 1.

To achieve an effective print, the production requirements must be contained in the manufacturing file. Most efforts for AM file standards appear to be focused on standardising the definition of CAD geometry such as improving the STL file through $\mathrm{AMF}$ and $3 \mathrm{MF}$ initiatives [11]. In addition to the CAD geometry, other important build information and data requirements that are needed include object orientation, support structures, slice structures, machine paths, object packing information, and tolerance data [10]. According to Hiller and Lipson [12], a robust file format should consider aspects of technology independence, simplicity, scalability, and future compatibility. For example, information such as geometrical data should be independent of manufacturing processes, while other information such as tool paths should be dependent on the manufacturing process [2]. This means that information can be considered to be machine or device dependent. This is particularly important for laser- and electron-beam AM processes where relevant data includes the sequence and timing of deposition paths that influence the overall quality and composition of eventual product with regards to stress and microstructure [8]. Other researchers also reported that some information can be lost during the stages of manufacture. For example, the original geometry information (the native CAD file) and the tessellated features can be displaced after the slicing process. Slicing is used to convert a 3D CAD model into a set of instructions for the AM machine in the form of a machine G-code. As there is no standard framework for the exchange of data for the AM production stages, Nassar and Reutzel [8] and Kim et al. [9], proposed four additional file formats in addition to the existing AMF format. They suggested an "AMSF" format that could contain information about the "slices", whereby the "AMPF" extension would capture data on path planning and process parameters; "AMQF" would be used for sensor data and as a qualification record; while "AMVF" would be used in the last stages of verification and validation phase.

\subsection{An overview of additive manufacturing data formats}

Today, the most commonly used file format for transferring the data model for AM is the STL file format. STL is a digital format that is used to store tessellated surface information. It has been recognised that the STL format has several shortcomings that reduce the suitability of using this format for newer AM machines with multi-nozzle and functionally graded materials capabilities. STL files are prone to redundant information and geometrical defects such as 
1. A geometric model, also known as CAD model, is designed. Alternatively, the geometry of a physical artefact is scanned into the computer.

2. This leads to raw tessellated data that might not yet fit to the requirements of AM.



3. This leads to a watertight model being generated.

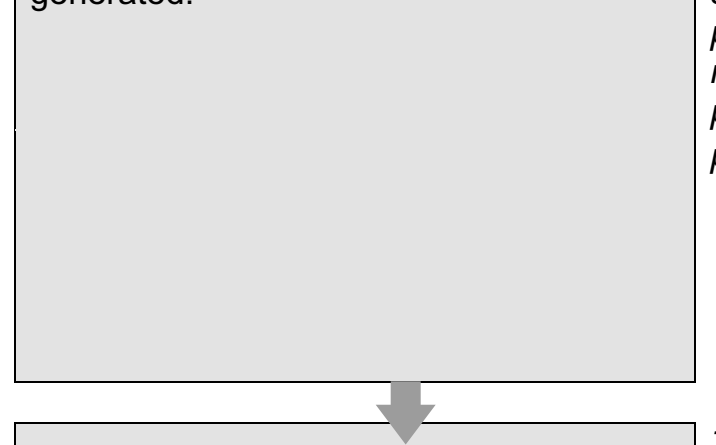

4. This leads to a build file.

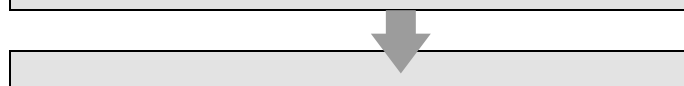

5. This leads to machine instructions.

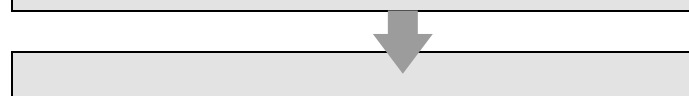

6. This leads to the built part.

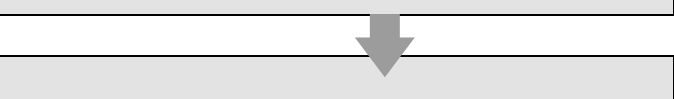

7. This leads to the finished part.

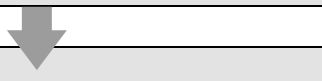

8. This leads to the validated part.
The data of either the geometric model or the point cloud from the geometry scan is reformed into tessellated data.

From the raw tessellated data, a so-called watertight model with a manifold, i.e. unbroken surface, is created. The tessellated model is further cleaned and fixed.

Depending on the intended AM production process, the watertight model is prepared for build by preparing support structures, setting build orientation, slicing the model into many separate layers and setting up machine paths. By optimizing the manufacturing cost, material waste, and print time, the optimal process planning will be determined to provide the required data and parameters.

The build file is translated into codes that describe specific machine operations. During the specific process, the machineinterpretable language will be represented by the specific build file, i.e.: STL, AMF, 3MF, or even STEP.

Executing the machine instructions leads to manufacturing of the part according to the execution of programming in the specific controller.

The built part is post-processed, e.g. through removal of support structures, sandblasting, surface finishing etc. It is used to meet the original requirements

The finished part is tested, e.g. its measurements are compared for compliance with predetermined geometric or material tolerances.

It will be used to validate the print part whether it meets the design requirements. If not, it will give a direct feedback to design stage, and modify the original requirements or optimizing parameters.

Fig. 1 The Complete AM process [9] 
Table 1 The AM Process, from Nassar and Reutzel [8] and Kim et al. [9]

\begin{tabular}{|c|c|}
\hline Stages of AM & Sub-Stages \\
\hline Part design & $\begin{array}{l}\text { Create geometric design } \\
\text { Tessellate geometry } \\
\text { Prepare watertight model } \\
\text { Slice model, set orientation, support structure }\end{array}$ \\
\hline Process planning & $\begin{array}{l}\text { Plan path } \\
\text { Create machine code }\end{array}$ \\
\hline Execution & $\begin{array}{l}\text { Manufacture } \\
\text { Remove support structure and surface treatment }\end{array}$ \\
\hline Verification & $\begin{array}{l}\text { Test part } \\
\text { Validate part }\end{array}$ \\
\hline
\end{tabular}

missing, overlapping and degenerate facets, guarding against and repairing of which is computationally and procedurally expensive. The STL file also lacks the provision to store material, texture, colour, measurement or structural information [6]. The surface triangle information model for STL does not provide inherent mechanisms to retain manifold surface information. As a result, a number of proprietary alternatives for 3D model data storage have been proposed and efforts are underway to introduce standards to comprehensively fulfil the design requirements of AM. An overview of the advantages and disadvantages of the file formats frequently associated with AM use is presented in Table 2 [10]; ISO TC184 SC4 WG3 [12, 13]; 3MF [5, 14, 15], p. 261; [2]; ISO TC184 SC1 WG7 [16].

The most prominent effort to date is the AMF format which is an official ISO/ASTM standard for AM. Another file format for AM is $3 \mathrm{MF}$ that arose as an effort to bridge the gap between hardware and software systems. Both are based on the extensible mark-up language (XML), which means that the formats follow a standardised, text-based, humanreadable encoding format following the open XML specification [17]. Both AMF and 3MF are open and evolving standards that are intended to handle large amounts of design and geometric data required by AM processes. It remains to be seen whether AM hardware and software vendors will refrain from proliferating their own controlled, closedsource formats or to adopt a single industry-wide framework that can cope with the complexity of different AM processes and machines. In the manufacturing spectrum, an alternative approach to the standardisation of AM specific file formats are STEP and STEP-NC machining standards. STEP standards differ from other standards, which is not only product model, but also print format. It provides a broad range of product information descriptions, such as geometry information, material information, and other related specifications and requirements. However, STEP-NC can be viewed as an extended STEP standard. Therefore, STEP-compliant product model can involve the entire product lifecycle. They are efforts from organisations including ISO and ASTM to standardise product and production related information across a number of manufacturing processes. To date, both standards aim to provide extensions that can support AM infrastructure and services. Unlike STL, AMF and 3MF formats, the STEP format includes related geometric and tessellated model data. STEP-NC has a more ambitious aim by building on STEP to include more processing information, but avoiding the tessellated model and to only contain the geometric model.

\subsection{Data interface problems of additive manufacturing data formats}

In the previous section, we provided an overview of the AM process and file formats for data exchange and sharing. From a review of the literature, we identified notable advantages and disadvantages of existing file formats. While we did not find any literature on context-dependency in data requirements of AM data transfer, there is a very clear distinction that separates the use of AM for rapid prototyping and AM as an industrial manufacturing process. For rapid prototyping, features such as exact tolerance adherence and material gradation are perceived to be of minor importance, and therefore the STL format appears to continue to be seen as sufficient for single-material prints. The current de-facto

Table 2 Advantages and disadvantages of examined file formats

\begin{tabular}{lllll}
\hline STL format & STEP format & STEP-NC format & AMF format & 3MF format \\
\hline $\begin{array}{l}\text { Advantages } \\
\begin{array}{c}\text { Simplicity for processing, } \\
\text { highly portable }\end{array}\end{array}$ & $\begin{array}{l}\text { Supports } \\
\text { precision } \\
\text { manufacturing require- } \\
\text { ments }\end{array}$ & $\begin{array}{l}\text { Supports } \\
\text { precision } \\
\text { manufacturing require- } \\
\text { ments }\end{array}$ & $\begin{array}{c}\text { Wide support of AM } \\
\text { capabilities } \\
\text { and future } \\
\text { extensibility }\end{array}$ & $\begin{array}{c}\text { Sophisticated process and } \\
\text { metadata support for } \\
\text { inter-operability }\end{array}$ \\
$\begin{array}{c}\text { Disadvantages } \\
\begin{array}{c}\text { No support for modern } \\
\text { AM, error-prone, poor } \\
\text { scalability }\end{array}\end{array}$ & Computationally complex & $\begin{array}{c}\text { Paradigmatically different, } \\
\text { no tessellated model }\end{array}$ & $\begin{array}{c}\text { Currently less widely } \\
\text { adopted }\end{array}$ & $\begin{array}{c}\text { Currently less widely } \\
\text { adopted }\end{array}$ \\
\hline
\end{tabular}


standard of using STL to describe surfaces has some shortcomings due to its inability to describe the properties of the object such as material gradation and colour. First, as there is an increased demand for such features to be used by AM, the use of STL is less capable to meet the demands of the next generation of AM systems. Second, while some of these issues have been addressed by newer file formats such as AMF and STEP-NC, the formats are usually software or hardware-dependent and the build files are still sometimes difficult to be translated across different machine systems. STEP-compliant NC physical file not only describe CAD geometry and design information but also represent the definitions of tools and manufacturing process. Third, AM as an industrial process should be capable of going beyond the mere volumetric and geometric description of an artefact to be manufactured. Some production parameters have relevance to artefact integrity and need to be contained in the file for production such as the built orientation or the melt pool size. Finally, the majority of current models favour tessellated descriptions of volumes. A model with originally smooth surfaces will be represented as a number of edges and vertices. Through the tessellation process, it is inevitable that some precision will be lost. When it was originally conceived with limited computing power, tessellation was seen as an efficient method that could simplify the necessary calculations for slicing. However, as processing power in modern computers has increased, data formats should now enable direct processing of geometric models. The authors believe that future requirements for an AM file format based on a hypothetical RDM scenario should include support for Intellectual Property, quality assurance, and product liability. An RDM scenario where the end user can modify parts might also take into account limited 3D modelling and engineering skill as well as capturing the knowledge between end users and conventional artefact modellers. As such, an RDM-compatible AM data transfer standard should include features that can be modified and other manufacturing related features such as the minimum and maximum wall thicknesses in artefacts should be locked and not editable.

\subsection{Additive manufacturing in a re-distributed manufacturing context}

To illustrate the features of AM in a RDM scenario, we define $\mathrm{AM}$ as a production process and RDM as a hypothetical manufacturing scenario that takes place in the future. The manufacturing process transforms raw materials into specifically designed physical artefacts. A number of manufacturing techniques, business schemas, and global supply chains have been established in today's landscape of modern production. Depending on the component, traditional manufacturing is still usually defined by geographically concentrated production centres that are aligned with an already established supply chain network. In such manufacturing centres, large amounts of generally identical items are produced for mass consumption and shipped to remote locations. The position of manufacturing centres is also subject to the availability of technology and manpower. In modern times, the aspect of shipping has become a key factor in the face of the relative efficiency of economies of scale, meaning that it is cheaper to ship products than to set up additional production plants. Industrial development has been predicted to move away from cheap mass production towards customised and personalised products. Manufacturing industry will move towards industrial capacity being re-allocated into reconfigurable factories for continually changing supply chains, super factories for complex products, and even domestic production [18]. Accordingly, five strategic themes have been identified for the future of manufacturing by InnovateUK which is a UK non-departmental public body set up to accelerate UK economic growth by stimulating and supporting business-led innovation, focusing on resource efficiency, manufacturing systems, materials integration, manufacturing processes, and business models. Manufacturing systems and processes, in particular, refer to the creation of more efficient and effective manufacturing models by developing new, agile, and increasingly cost-effective manufacturing processes. There is potential for manufacturing to become even more flexible and adaptive, specifically by applying Additive Manufacturing and to emphasise on high-value manufacturing (HVM). HVM refers to "the application of leading-edge technical knowledge and expertise for the creation of products, production services and associated services" [19], as well as "the reduction of material and energy use in production, and the repatriation or on-shoring of production" (ibid). A part of this is a trend towards Distributed Manufacturing, which is an "ondemand, local manufacturing, made possible by combining digital technologies with new production processes" [20]. Distributed Manufacturing does away with manufacturing centres. In this scenario, manufacturing is de-centralised and the final product is manufactured close to the eventual customer. This leads to the concept of Re-Distributed Manufacturing (RDM). RDM is defined as technology, systems and strategies that have the potential to change the economics and organisation of manufacturing, particularly with regard to location and scale [21]. RDM represents the production of evolved, smart and sustainable products, designed and produced locally using customer input and collaboration. As such, RDM poses future social, technological and economic challenges. One of the key challenges for RDM is how to enable competitive local production, presumably through the consumer or small local manufacturers. In this context, AM has been identified as a technology that might lead to new business models [22] and disrupt the current dominance of cheap global shipping and economies of scale since the 
principle of $\mathrm{AM}$ as a system that can, in principle, produce anything eliminates the need for specialised manufacturing facilities and reduces the efficiency advantage of scale economies. There are limitations of AM that cast doubt on the notion that it might replace mass-production technologies for serial manufacturing of cheap items [23]. However, it is still conceivable that AM would feature prominently in a combined approach where modern and smart products are modularised, with complex or consumable parts produced in traditional manufacturing, and personalised parts produced by local manufacturing or consumers. Based on this, the role of AM in an RDM environment can be defined as the manufacturing of adapted, customer-configured or individualised artefacts close to the customers' location. This would lead to a number of conceivable use cases for implementing AM in an RDM scenario. Thiesse et al. [24] referred to this scenario as: "A company constructs functional product parts whereas the customer contributes towards the product design. The production is then carried out by a service provider." On one end of the user spectrum, a user might download the desired 3D model for free or for a fee. On the other end, a user might completely model the desired artefact autonomously. In between exists a scenario where a downloaded model is adapted to fit the user's needs. The final model is printed either by the user on his or her own AM machine or through an AM service, depending on product requirements such as the material, resolution or quality. For example, material extrusion systems might be suitable for some users and sufficient for a number of parts, whereas powder-based materials might be more suitable for high-quality or high-performance parts. Systems using this technology are less likely to be at the disposal of typical end users. However, hybrid solutions are also conceivable where only some parts, specifically those that are customisable, are modified and printed by the end user, whereas the core part is manufactured remotely [25]. Commercial and non-commercial model repositories such as thingyverse (www.thingyverse.com), Shapeways (www.shapeways.com), Ponoko (www.ponoko.com), and Sculpteo (www.sculpteo.com) and other AM vendors are some examples.

\section{Empirical methodology}

The empirical part of this research aims to determine (i) who are the users and beneficiaries of the AM data transfer standards for RDM, (ii) what characteristics are required for AM data transfer standards in a RDM scenario, (iii) which of the existing AM data exchange standards has the greatest competitive advantage in a RDM scenario, (iv) how such standards could affect the RDM landscape, and (v) whether or not there are opportunities for an open architecture AM data exchange standard. A central challenge for the empirical method is the selection of the data collection technique. AM is an existing technology and its use is an actual, measurable phenomenon and the use of AM and its data requirements are open to scientific enquiry. However, this research is not concerned with the data exchange standard requirements of today's AM. Instead, it aims to determine the data exchange standard requirements of AM in a future RDM scenario. It is based on a hypothetical future scenario envisaged by expert assumptions or predictions. RDM, in particular, includes the involvement of customers and/or users and implies that they have an impact on the artefact through personalisation or individualisation. In this context, it might be important to consider the socio-technical implications of customer/ user involvement. Since common development and analysis techniques are vague, it was instead decided to obtain a view of the needs of a possible AM data exchange format in an RDM scenario from academics and experts using surveys and focus groups.

A survey was constructed to answer research questions RQ1 to RQ5. The questions about the impact of AM data transfer standards, as well as about users and beneficiaries, are relatively open due to RDM being a future envisaged scenario. Those questions require subjective predictions on two counts: first, a prediction of how RDM as a manufacturing scenario will occur, and second, how AM data transfer standards will fit into such a scenario. RQ3 is methodologically conducive to RQ1: an opinion on the impact of data transfer standards would also imply the latter's users and beneficiaries. On the other hand, questions about the competitive advantages of existing, and required characteristics of potential, data transfer standards in the context of RDM are at least in part anchored in actual capabilities, requirements and limitations of existing data transfer standards and of AM. RQ5 is also conducive to RQ2: once the required characteristics for an AM standard have been identified, these can be used to evaluate against existing standards. Due to the abstract nature of the survey, i.e. its focus on a future scenario and its lack of connection to current practice, it was recognised that obtaining a high response rate could be a challenge. To facilitate a response rate that was as high as possible, it was therefore decided to create a short and concise survey. For the rating, participants were given the option to rank each feature on a scale from "unimportant" to "very important", with "somewhat important" and "important" as intermediary options. For later analysis, these options were weighted from 4 (most important) to 1 (unimportant). Alternatively, the option "feature unclear" was available for participants who felt that they were not able to rate a specific feature. To find out whether the participants were familiar with the term RDM, they were asked if they had heard of RDM before (Q1) to contextualise the RDM-specific questions, as it was assumed that participants, particularly those 
from industry and non-academic areas might not be familiar with it and the term might be misunderstood. The next question asked what $\mathrm{AM}$ data standards the respondent was using (Q2), and why (Q3). These questions were used as warm-up questions due to their potential to augment the answers on current data transfer use, its reasons and its issues. To elicit the participants' views and opinions on the impact (RQ3), including users and beneficiaries (RQ1) of AM data transfer standards for RDM, the survey progressed with a paraphrased description of an RDM scenario and asked how, in such a scenario, an AM data exchange standard would affect RDM processes (Q4) and industry (Q5). Q3, Q4 and Q5 would be analysed following qualitative thematic analysis, i.e. from the occurrence of common themes shown in the results.

To determine the characteristics required for an AM data exchange standard (RQ5) and to identify the standard with the greatest competitive advantage in an RDM scenario (RQ2), participants were asked to rate various features of AM data exchange formats that could potentially be of importance in a hypothetical RDM scenario (Q6). To keep the survey short, this was designed to fit into a single A4 page and limited the rating to 20 features related to an RDM scenario. Within the features, the first of those were suggested from RDM scenarios provided in relevant literature. For example, customisation and user involvement features in RDM scenarios were discussed by Charnleyet al. [25] and this was understood as a major requirement for a data transfer standard leading to the item "multi-user editing". Other selected RDM-related features were "copyright information" and "encryption". Additionally, the item "open architecture" was included in the list to understand how participants judged the need for an open standard (RQ4). The remaining features were populated by the most prominent factors discussed in academic literature on AM and its file formats and standards, as well as definitions [12]; $3 \mathrm{MF}[5,14,15]$ as shown in Table 3. The survey closed with two biographical questions for qualifying the sample, country of residence (Q7) and occupation (Q8), followed by optional input of name (Q9) and email address (Q10). The complete survey is located in Appendix A.

The participants were consistently recruited from a number of academic and industrial events related to AM and RDM, including ISO/ASTM meetings and industry fairs such as Formnext, and the RDM workshop in Cambridge. An overview of the data collection is shown in Table 4. Additional participants were recruited from the professional and personal network of researchers. The recruitment strategy led to a non-probabilistic purposive sample of experts

Table 3 AM features for rating

\begin{tabular}{|c|c|c|}
\hline No. & Feature & Definition \\
\hline 1 & Arbitrary metadata & Provisions that allow for the storage of arbitrary data as deemed by the designer \\
\hline 2 & Colour textures & The ability to define and represent printed surface patterns \\
\hline 3 & In-material colours & The ability to define and represent colours of print materials \\
\hline 4 & Compression & $\begin{array}{l}\text { A definition on how to increase information density or reduce overall file size for archiving or transmission } \\
\text { purposes }\end{array}$ \\
\hline 5 & Encryption & A definition on how to protect model and product data from reading or editing by non-authorised parties \\
\hline 6 & Copyright information & $\begin{array}{l}\text { The ability to explicitly define copyright information related to the artefact representation as part of the stand- } \\
\text { ard }\end{array}$ \\
\hline 7 & Curvature representation & The ability of the artefact to represent non-flat surfaces precisely instead of approximately \\
\hline 8 & Geometric representation & The ability to store an artefact's representation through geometric approximations such as vectors or triangles \\
\hline 9 & Manufacturing tolerances & Features that explicitly define target envelopes for physical artefacts \\
\hline 10 & Material gradation & $\begin{array}{l}\text { The ability to represent gradual changes in material property such as a gradual graduation from one material to } \\
\text { another }\end{array}$ \\
\hline 11 & Multiple object support & The ability to define more than one artefact in a file \\
\hline 12 & Multi-user editing & The ability for multiple users to design or edit an artefact model \\
\hline 13 & Object instance support & The ability to replicate identical geometries by referencing a previously defined geometry \\
\hline 14 & Print queues & Features that explicitly refer to printer job management \\
\hline 15 & Regular internal structures & The definition of the triangles that make up the geometric representation of the artefact \\
\hline 16 & Surface structures & The definition of surface structures separate from the geometric representation of the artefact \\
\hline 17 & Tool paths & The explicit definition of machine movements during manufacturing such as extruder or melting laser passes \\
\hline 18 & Units of measurement & Explicit dimensions as part of an artefacts' representation \\
\hline 19 & Voxel representation & The provision to store artefact geometry as regionally delimited three-dimensional pixels in a regular grid \\
\hline 20 & Open architecture & $\begin{array}{l}\text { A free and open international standard document file format that can be imported into any CAD software capa- } \\
\text { ble of working with that type of file, and then sent for production }\end{array}$ \\
\hline
\end{tabular}


Table 4 Data collection and attended events

\begin{tabular}{|c|c|c|}
\hline Event & Activity & Purpose \\
\hline ISO STEP meeting & Standardisation meeting & Participant recruitment, information exchange \\
\hline Formnext Frankfurt & Industry fair & Participant recruitment, information exchange \\
\hline RDM Workshop & Workshop & Information exchange \\
\hline $\begin{array}{l}\text { 3DP-RDM dissemination workshop in } \\
\text { Cambridge }\end{array}$ & Workshop & $\begin{array}{l}\text { Participant recruitment, data collection, research approach dissemination, } \\
\text { information exchange }\end{array}$ \\
\hline ISO TC261/ASTM F42 Joint meeting & Standardisation meeting & $\begin{array}{l}\text { Participant recruitment, data collection, result dissemination, information } \\
\text { exchange }\end{array}$ \\
\hline DSM Seminar & Seminar & Result dissemination \\
\hline ISO TC261/ASTM F42 Joint meeting & Standardisation meeting & Result dissemination and discussion \\
\hline
\end{tabular}

in the areas of AM, including accomplished researchers and practitioners.

\section{Results and discussion}

The survey was handed out as a paper copy to 21 attendants during a meeting at an ISO/ASTM meeting with six participants fully completing the survey on paper. Additionally, the survey was sent as an interactive document via an email attachment to 132 attendants and other 15 attendants of the ISO/ASTM meeting who did not complete or return the paper copy. Eleven declined to participate, citing as reason a lack of competence in either AM or RDM $(n=9)$, a lack of time $(n=1)$, or company policy $(n=1)$, and 19 returned the completed surveys. Altogether, paper and email submissions resulted in 27 completed responses. Additionally, two focus groups were conducted with RDM experts during a workshop held in Cambridge. Finally, expert interviews were conducted in London for validation of the results. Of the survey participants, ten resided in Europe, nine in North America, and four in South East-Asia. Occupationally, the sample was balanced with engineers and researchers each comprising seven participants of the sample. Six participants were managers, and one participant worked in a sales position. Two participants did not disclose their occupation (Tables 5, 6).

There were 23 participants at the two focus groups but no biographical data was collected from them. Two-thirds of the participants $(n=15)$ had heard of re-distributed manufacturing or RDM, and for the remaining participants $(n=8)$ the term was new. In the survey, all participants answered Q1 and Q2, two participants did not answer Q3, three participants did not answer both Q4 and Q5, and two additional participants did not answer Q5. All participants completed the rating (Q6) and gave their country of residence (Q7). One participant did not state an occupation (Q8). Almost every participant was actively using the STL format. Other standards that the respondents pointed out were $. \mathrm{OBJ}, . \mathrm{AMF}$
Table 5 File Formats used by participants

\begin{tabular}{lllll}
\hline & STL & OBJ & AMF & STEP \\
\hline Participants & 26 & 5 & 3 & 2 \\
\hline
\end{tabular}

Table 6 Motivations for the choice of file format

\begin{tabular}{lllll}
\hline & $\begin{array}{l}\text { Compat- } \\
\text { ibility }\end{array}$ & $\begin{array}{l}\text { Hardware } \\
\text { or software } \\
\text { requirement }\end{array}$ & $\begin{array}{l}\text { Format prop- Usability } \\
\text { erties }\end{array}$ \\
\hline $\begin{array}{c}\text { Format } \\
\text { choice }\end{array}$ & 11 & 6 & 3 & 2 \\
\hline
\end{tabular}

and .STEP. A number of standards were used by only single participants, including .3MF, .CLI, .IGES, .MAGICS, .MGX, .RP, .VML, and .ZPR.

Q3 asked for the motivations behind their file format choices. 11 participants stated that they chose based on compatibility in the sense of portability between the application and hardware. Six participants stated that their choice was determined by either the hardware or software that could only accept the chosen format. Only two participants chose their file format each for usability reasons such as file size or ease of use, or because either customers or superiors required them to do so.

Regarding the responses to Q6, which is to rate the importance of each feature (shown in Table 3) on a scale from unimportant to very important, the average rating over all features was 3.01, i.e. on average, each feature was rated as "important", with nine of the 20 features rated above average importance. The highest rating was "regular internal structures/lattices" with an average of 3.61, and the lowest was "print queues" with an average of 2.44. 11 of the 20 features received at least one "feature unclear" rating, with "object instances" being the most unclear feature. The complete descriptive statistics are shown in Table 7. 
Table 7 Rating results compared to format features

\begin{tabular}{|c|c|c|c|c|c|c|c|c|c|}
\hline & Mean & Median & Mode & ncl. & STL & $\mathrm{AMF}$ & $3 \mathrm{MF}$ & STEP & STEP-NC \\
\hline Internal structures/lattices & 3.67 & 4 & 4 & 0 & & $\checkmark$ & & & \\
\hline Manufacturing tolerances & 3.56 & 4 & 4 & 0 & & $\checkmark$ & & $\checkmark$ & $\checkmark$ \\
\hline Geometric representation & 3.52 & 4 & 4 & 0 & $\checkmark$ & $\checkmark$ & $\checkmark$ & $\checkmark$ & $\checkmark$ \\
\hline Curvature representation & 3.48 & 4 & 4 & 2 & & $\checkmark$ & & & $\checkmark$ \\
\hline Units of measurement & 3.44 & 4 & 4 & 0 & & $\checkmark$ & $\checkmark$ & & $\checkmark$ \\
\hline Material gradation & 3.37 & 3 & 3 & 0 & & $\checkmark$ & & $\checkmark$ & $\checkmark$ \\
\hline Surface structures/textures & 3.37 & 4 & 4 & 0 & & $\checkmark$ & & & $\checkmark$ \\
\hline Multiple objects & 3.22 & 3 & 3 & 4 & & $\checkmark$ & $\checkmark$ & $\checkmark$ & $\checkmark$ \\
\hline Object instances & 3.16 & 3 & 3 & 8 & & $\checkmark$ & $\checkmark$ & & $\checkmark$ \\
\hline Open architecture & 2.92 & 3 & 4 & 1 & & $\checkmark$ & $\checkmark$ & $\checkmark$ & $\checkmark$ \\
\hline Copyright information & 2.85 & 3 & 2 & 1 & & & $\checkmark$ & $\checkmark$ & \\
\hline Compression & 2.81 & 3 & 3 & 1 & & $\checkmark$ & & & $\checkmark$ \\
\hline Tool paths & 2.76 & 3 & 3 & 2 & & & & & $\checkmark$ \\
\hline Voxel representation & 2.72 & 3 & 3 & 2 & & & & & \\
\hline Encryption & 2.72 & 3 & 3 & 1 & & & & & \\
\hline In-material colours & 2.63 & 2 & 2 & 0 & & $\checkmark$ & $\checkmark$ & $\checkmark$ & $\checkmark$ \\
\hline Arbitrary metadata & 2.63 & 2.5 & 2 & 3 & & $\checkmark$ & $\checkmark$ & & $\checkmark$ \\
\hline Multi-user editing & 2.58 & 2.5 & 2 & 3 & & & & & \\
\hline Colour textures & 2.42 & 2 & 2 & 1 & & $\checkmark$ & $\checkmark$ & & $\checkmark$ \\
\hline Print queues & 2.24 & 2 & 1 & 6 & & & $\checkmark$ & & \\
\hline & \multicolumn{4}{|c|}{ No. of supported features } & 1 & 14 & 10 & 7 & 14 \\
\hline & \multicolumn{4}{|c|}{ Supported features (weight/avg.) } & 0 & 13.53 & 8.40 & 7.26 & 14.43 \\
\hline & \multicolumn{4}{|c|}{$\begin{array}{l}\text { Supported features (weight/ } \\
\text { mod.) }\end{array}$} & 0 & 42 & 23 & 22 & 44 \\
\hline & \multicolumn{4}{|c|}{ Supported features (weight/rank) } & 0 & 0.74 & 0.32 & 0.41 & 0.78 \\
\hline
\end{tabular}

\subsection{RQ1: what impact could AM data exchange standards have on an RDM landscape?}

This question was answered by a qualitative text analysis of survey questions Q4 and Q5. Half of the participants $(n=13)$ stated that an AM data exchange standard would improve the manufacturing process mostly through overall simplification, being able to automate the tessellation step, specifically the step from CAD to a manufactured model $(n=5)$, and a decrease of variation among parts from identical data $(n=4)$. Four participants stated that the AM data transfer standard would aid in general manufacturing improvements such as the homogenisation of interfaces for manufacturing machines or bridging software and hardware gaps, speeding up the manufacturing process and increasing the process flexibility. Software and hardware compatibility were seen by five participants as a transformative outcome for the RDM landscape. Some participants predicted the standardisation of AM data transfer formats would support future improvements of AM in areas such as model optimisation and part analysis $(n=5)$. Further, the impact on the industry was seen by some participants through a future adoption of AM in additional areas of manufacturing $(n=5)$, an active involvement of end users in manufacturing $(n=3)$, and enabling even more possible hardware geometries $(n=2)$. An improvement in AM model representation, possibly through alternatives to tessellation, was expected by three participants, and a better coverage of information required for an AM manufacturing process by two participants. Further expected and predicted benefits of an AM data standard include promoting location-independent manufacturing, improved collaboration across disciplines, increased competition in the sector of AM service vendors, and improved reputation of the AM industry.

\subsection{RQ2: who are the users and beneficiaries of AM data exchange standards?}

This question was answered by identifying the users and beneficiaries from Q4 and Q5 in the participants' responses. A clear majority of responses suggested that manufacturers, i.e. the producers of AM parts, are the main beneficiaries of AM data transfer standards $(n=20)$. These were followed by end users $(n=8)$ and tool providers $(n=6)$. Tool providers such as developers of mesh optimisers would profit from easy access to an official standard as well as the possibility of reaching the entire market by supporting a single, comprehensive standard supporting the whole range of AM systems. End users, i.e. 
the eventual benefactors of AM products, would profit from a number of effects, including more arbitrary artefact shapes and consideration of exclusive end user concerns such as privacy, in the case of AM medical prostheses. Industrial customers were identified as beneficiaries $(n=9)$ through an improved access to AM and an increased ability of AM to produce arbitrarily shaped products. A few participants identified the general public $(n=3)$ as benefiting, through a reduced impact of AM production, and also developers of AM machines $(n=2)$, through further improvement of AM data transfer formats enabled through standards.

\subsection{RQ3: What characteristics are needed to manage the AM data exchange standards for RDM?}

The five features deemed most important by the participants were regular internal structures/lattices, manufacturing tolerances, geometric representation, curvature representation, and surface structures. The full rating result, ordered by average rating, is presented in Table 7. Some participants used the free text fields to express their expectation that a future AM data transfer standard would come with features such as enabling copyright and privacy protection, in particular for bespoke medical artefacts such as prostheses.

\subsection{RQ4: which AM data exchange standard has the greatest competitive advantage for an RDM landscape?}

Table 7 lists the rating results ordered by average and the supported features per standard. To determine which data exchange standard has the greatest competitive advantage, the standards themselves needed to be ranked. We adopted the gold-first ranking, whereby the standard supporting the most important feature for AM data transfer formats is ranked with the highest score. In the event of a tie, support for the next-most-important feature determines the ranking, until there is a clear order. However, such a ranking would ignore the number of features actually supported-it is conceivable that a standard supporting all but one feature might lose out to a standard supporting only one feature, which by chance could have been ranked with the highest score. Alternatively, the highest score could be given to the standard with the most supported features. Yet another alternative was to apply a system of weighed ranking, where each feature would be assigned a weight, e.g. according to its rank, its average importance, or its importance mode. The last four measures are shown in Table 7 . The most important feature, regular internal structures, is only supported by AMF. Interestingly, STEP-NC covers the same number features when compared to AMF, $3 \mathrm{MF}$ or STEP but STEP-NC includes "toolpaths" at the expense of "internal structures". STEP-NC is also ranked above AMF when weighed by average feature importance, modal feature importance, or feature rank. The research suggests that the AM data exchange standard most suitable for an RDM scenario is STEP-NC. This is paradoxical as the STEP-NC standard is still in the process of standardising interfaces for machining and industrial scale production for AM. Beyond the question is whether the STEP-NC standard should have been eligible for comparison in this research to begin with, as the research results can be seen as a tentative suggestion that STEP-NC already supports a wide range of features that are rated desirable. AMF and the fairly new $3 \mathrm{MF}$ format were expected to come out top in the competitiveness ranking. While AMF came second to STEP-NC only marginally, $3 \mathrm{MF}$ did not perform well, although some of its features are supported neither by AMF nor STEP-NC. It should also be argued that internal structures which are contained in AMF are more important than toolpath features for AM because geometric data is a key inherent feature for representation. Overall, it appears that in their current versions, AMF is more sophisticated than $3 \mathrm{MF}$.

\subsection{RQ5: are there opportunities for an open architecture AM data exchange standard?}

In the focus group sessions, it was acknowledged that commercial interests could drift towards proprietary standards. At the same time, focus group participants emphasised that standards needed to be accessible across disciplines for interoperability in the context of RDM. "Open architecture" was rated 2.92 on average, somewhat below the overall average "important" rating. Only one participant did not rate the feature. The mode, i.e. most common rating, for "open architecture" was four ("very important"), and it was the feature with the biggest gap between average and mode. When compared to all other features, participants were unusually split in their opinion on having an "open architecture". Altogether, "open architecture" received ten ratings of "very important", and seven ratings each for "important" or "somewhat important", but also three ratings for "unimportant". The topic of open architecture was also mentioned in the open text answers of Q3 and Q4. Two participants predicted that open standards could reduce the barrier of entry for the developers of software tools, leading to more competition among existing software tools such as mesh optimisers, and also to develop other new improvements for AM data exchange formats. 


\section{Conclusions}

This research has extended our understanding of the requirements of AM data exchange formats in an RDM scenario. As RDM is a hypothetical scenario, the information requirements were developed from views solicited through surveys and focus group sessions involving academics, experts, researchers and practitioners in the field. The results showed that the establishment of an AM data exchange standard for a RDM scenario has the potential for positive impact on the AM process, mostly directly benefiting practitioners of AM technology. Further, a robust and comprehensive standard might facilitate ongoing development of AM technology. The findings also show the importance of including certain features for manufacturing processes and artefact representation for future AM data exchange standards. The rating results for an AM data exchange standard suggest that the information requirements are not widely divergent from today's AM use where more important features focus on efficiency and effectiveness of the digital artefact representation and its general transformation into a physical product. Similarly, the most common themes in the open survey questions seem to be generally applicable to AM. While it is possible that the rating is specific to the RDM scenario, it seems likely that it was understandably difficult for participants to consider information requirements from a hypothetical point of view. It also raises the question whether there are actually RDM-specific requirements for a data exchange standard; and if yes, how relevant those features are? For example, as discussed earlier, the stipulation of user-configured manufacturing as part of RDM suggests multi-user editing as a requirement for AM information. However, it might be that the best location to handle this and other requirements stipulated by RDM is within the software. An assessment of information requirements in this research was further complicated by the different interpretations possible and available for an RDM scenario. We have observed a number of different views of RDM scenarios with varying features. While there are common themes, the view of RDM is naturally shaped by the research disciplines contributing to existing work. Some participants view that since in an RDM scenario, there is a reduced need for tooling, factories would no longer need to be located geographically close to each other. Other views focus on a re-shoring of manufacturing jobs due to reduced economies of scale. Yet other views assume reduced ecological impact through increased product life spans through individualisation. Views of the impact of RDM on technology, economy and society are diverse. Overall, more participants had knowledge of RDM than assumed at the start of the research, but the interpretive diversity could have had an impact on the homogeneity of predicted information requirements. Our research results contributed to an understanding of the expected aims and objectives as well as the beneficiaries of a future, comprehensive AM data exchange standard for RDM. Specifically, such a standard is most likely to improve the manufacturing process. There is a strong emphasis on the technical capabilities of such a standard, with human and sociotechnical aspects of AM finding less consideration. Accordingly, these results benefit developers of future AM data exchange standards as well as AM operators. For example, there is an emerging trend towards multi-material AM and scholars have proposed a representation schema for multi-material attributes to sliced files for AM using a combination of material and geometry indices [26]. In conclusion, this research suggests that STL is the de-facto standard due to technological legacy, but that it is desirable and important to move past this data exchange format so as to enable further progress AM through developing and adopting a more standardised medium of data exchange for RDM can take place. The research provides a groundwork through an empirically supported insight that considers the aspects and properties for future development of AM data exchange standards.

\section{Compliance with ethical standards}

Conflict of interest On behalf of all authors, the corresponding author states that there is no conflict of interest.

Open Access This article is distributed under the terms of the Creative Commons Attribution 4.0 International License (http://creativeco mmons.org/licenses/by/4.0/), which permits unrestricted use, distribution, and reproduction in any medium, provided you give appropriate credit to the original author(s) and the source, provide a link to the Creative Commons license, and indicate if changes were made.

\section{Appendix: A survey}

Q1:"Have you heard of Re-Distributed Manufacturing before?"

Q2: "What file formats are you using to pass 3D model information to an AM system (e.g. STL, AMF, OBJ, etc.)?"

Q3: "If applicable, what was the reason for the file format choice?"

Q4: "How would a data exchange standard have changed AM manufacturing processes?"

Q5:"How would a data exchange standard have changed the AM industry?"

Q6: "A large number of different file formats are used to send CAD data to AM machines. For this research, potential 
and proposed standards for AM data transfers were analysed. This research aims to understand how important these features are for AM. Please rate the importance of each feature on a scale from unimportant to very important."

Q7:"What is your country of residence?"

Q8: "What is your occupation?"

Q9: "What is your name?"

Q10: "What is your email address?"

\begin{tabular}{lllll}
\hline $\begin{array}{l}\text { Unim- } \\
\text { portant }\end{array}$ & $\begin{array}{l}\text { Some- } \\
\text { what } \\
\text { impor- } \\
\text { tant }\end{array}$ & $\begin{array}{l}\text { Impor- } \\
\text { tant }\end{array}$ & $\begin{array}{l}\text { Very } \\
\text { impor- } \\
\text { tant }\end{array}$ & $\begin{array}{l}\text { Feature } \\
\text { unclear }\end{array}$ \\
& & & \\
\hline
\end{tabular}

\begin{tabular}{l} 
Arbitrary \\
metadata \\
Colour \\
textures \\
In-material \\
colours \\
Compres- \\
sion \\
Encryption \\
Copyright \\
informa- \\
tion \\
Curvature \\
represen- \\
tation \\
Geometric \\
represen- \\
tation \\
Manufac- \\
turing \\
toler- \\
ances \\
Material \\
gradation \\
Multiple \\
objects \\
Multi-user \\
editing \\
Object \\
instances \\
Print \\
queues \\
Regular \\
internal \\
struc- \\
tures/ \\
lattices \\
struc- \\
tures/ \\
\hline
\end{tabular}

\begin{tabular}{|c|c|c|c|c|c|}
\hline & $\begin{array}{l}\text { Unim- } \\
\text { portant }\end{array}$ & $\begin{array}{l}\text { Some- } \\
\text { what } \\
\text { impor- } \\
\text { tant }\end{array}$ & $\begin{array}{l}\text { Impor- } \\
\text { tant }\end{array}$ & $\begin{array}{l}\text { Very } \\
\text { impor- } \\
\text { tant }\end{array}$ & $\begin{array}{l}\text { Feature } \\
\text { unclear }\end{array}$ \\
\hline \multicolumn{6}{|l|}{$\begin{array}{l}\text { Units of } \\
\text { measure- } \\
\text { ment }\end{array}$} \\
\hline \multicolumn{6}{|l|}{$\begin{array}{l}\text { Voxel } \\
\text { represen- } \\
\text { tation }\end{array}$} \\
\hline $\begin{array}{l}\text { Open } \\
\text { Architec- } \\
\text { ture }\end{array}$ & & & & & \\
\hline
\end{tabular}

\section{Appendix B: Focus group instructions}

Thank you for your participation. The aim of this research is to understand the details of the contribution AM can make to Re-Distributed Manufacturing (RDM). AM is the manufacturing of parts in layers directly from digital 3D model data. AM has the advantage of requiring no special tooling, enabling individualised products, and being mostly unaffected by economies of scale. RDM is a scenario in which location and scale of manufacturing is changed through technologies, systems and strategies. We are particularly interested in how you see the role of AM in RDM. We would like you to discuss the following:

Q1:“'Is openness, e.g. open standards, open formats, open software etc., a particular part of RDM?"

Q2: "How important is "openness" in an RDM scenario, e.g. "open software", "open standards", or "open hardware"? How would it be useful if manufacturers and end users could extend AM software and hardware?"

Q3: "For each of the seven aspects of RDM, discuss for four minutes whether AM might play a role."

\begin{tabular}{|c|c|c|}
\hline RDM aspect & $\begin{array}{l}\text { AM plays } \\
\text { a role? } \\
(y / n)\end{array}$ & $\begin{array}{l}\text { Please list in keywords how } \\
\text { AM might help achieve } \\
\text { aspects of RDM }\end{array}$ \\
\hline \multicolumn{3}{|l|}{ Localised manufacturing } \\
\hline \multicolumn{3}{|l|}{ Flexible manufacturing } \\
\hline \multicolumn{3}{|l|}{ Resilient manufacturing } \\
\hline \multicolumn{3}{|l|}{ Sustainable manufacturing } \\
\hline \multicolumn{3}{|l|}{$\begin{array}{l}\text { Resource efficient manu- } \\
\text { facturing }\end{array}$} \\
\hline \multicolumn{3}{|l|}{$\begin{array}{l}\text { Re-configurable manufac- } \\
\text { turing }\end{array}$} \\
\hline Replicable manufacturing & & \\
\hline Any other aspects & & \\
\hline
\end{tabular}




\section{References}

1. Frazier WE (2010) 'Direct digital manufacturing of metallic components: vision and roadmap', Direct Digital Manufacturing of Metallic Components: Affordable, Durable, and Structurally Efficient Airframes, at Solomons Island, MD. Available at http:// sffsymposium.engr.utexas.edu/Manuscripts/2010/2010-60-Frazi er.pdf. Accessed 18 Apr 2016

2. Lipman RR, McFarlane JS (2015) Exploring model-based engineering concepts for additive manufacturing. In: proceedings of the 26th solid freeform fabrication symposium. 26th Solid Freeform Fabrication Symposium, Austin. Available at http://www. researchgate.net/publication/281285803_Exploring_Model-Based _Engineering_Concepts_for_Additive_Manufacturing. Accessed 18 Apr 2016

3. Xiao J, Anwer N, Durupt A, Le Duigou J, Eynard B (2018) Information exchange standards for design, tolerancing and additive manufacturing: a research review. Int J Interact Des Manuf 12:495-504. https://doi.org/10.1007/s12008-017-0401-4

4. ISO TC184 SC4 (2014) Industrial automation systems and integration - Product data representation and exchange - Part 242: Application protocol: Managed model-based 3D engineering. ISO 10303-242:2014. ISO, Geneva

5. ISO TC261 WG4 (2015) ISO/ASTM 52915:2014 Specification for additive manufacturing file format (AMF) version 1.2. ISO/ ASTM International, Geneva

6. Chua CK, Leong KF (2015) 3D printing and additive manufacturing-principles and applications. World Scientific, Singapore

7. Royal Academy of Engineering (2013) Additive Manufacturing: opportunities and constraints. Available at http://www.raeng.org. uk/publications/reports/additive-manufacturing. Accessed $18 \mathrm{Apr}$ 2016

8. Nassar AR, Reutzel EW (2013) A proposed digital thread for additive manufacturing. International Solid Freeform Fabrication Symposium, Austin, Texas. Available at http://sffsymposium.engr. utexas.edu/Manuscripts/2013/2013-02-Nassar.pdf. Accessed 18 Apr 2016

9. Kim DB, Witherell P, Lipman R, Feng SC (2015) Streamlining the additive manufacturing digital spectrum: a systems approach. Addit Manuf 5:20-30. Available at http://www.sciencedirect.com/ science/article/pii/S2214860414000189 Accessed 18 Apr 2016

10. Pratt MJ, Bhatt AD, Dutta D, Lyons KW, Patil L, Sriram RD (2002) Progress towards an international standard for data transfer in rapid prototyping and layered manufacturing. Comput Aided Design 34(14):1111-1121. Available at http://www.sciencedirect. com/science/article/pii/S0010448501001890. Accessed 18 Apr 2016

11. Xiao J, Anwer N, Durupt A, Le Duigou J, Eynard B (2017) Standardisation focus on process planning and operations management for additive manufacturing. In: Eynard B, Nigrelli V, Oliveri S, Peris-Fajarnes G, Rizzuti S (eds) Advances on mechanics, design engineering and manufacturing. Springer, Cham, pp 223-232

12. Hiller JD, Lipson H (2009) 'STL 2.0: a proposal for a universal multi-material additive manufacturing file format'. In: proceedings of the solid freeform fabrication symposium. Solid Freeform Fabrication Symbposium 2009, Citeseer, pp 266-278. Available at http://sffsymposium.engr.utexas.edu/Manuscripts/2009/200923-Hiller.pdf. Accessed 18 Apr 2016

13. ISO TC184 SC4 WG3 (2006) Product data representation and exchange: application protocol: mechanical product definition for process planning using machining features. ISO 10303-224. ISO, Geneva

14. MF Consortium (2015) 3D manufacturing format - core specification and reference guide v1.1. Available at http://3mf.io/wp-conte nt/uploads/2016/03/3MFcoreSpec_1.1.pdf. Accessed 18 Apr 2016

15. ISO TC261 WG4 (2015) Report of AMF/STEP/STEP-NC Ad hoc group

16. ISO TC184 SC1 WG7 (2016) Data model for computerized numerical controllers-part 17: process data for additive manufacturing processes. ISO 14649-17, Geneva

17. Bray T, Paoli J, Sperberg-McQueen CM, Maler E, Yergeau M-K, Françoise (2008) Extensible markup language (XML) 1.0 (fifth edition). W3C. Available at https://www.w3.org/TR/REC-xml/. Accessed 18 Apr 2016

18. Foresight (2013) Future of manufacturing: a new era of opportunity and challenge for the UK-Publications-GOV.UK. Available at http://www.bis.gov.uk/foresight. Accessed 18 Apr 2016

19. Technology Strategy Board (2012) A landscape for the future of high value manufacturing in the UK. Available at https://hvm. catapult.org.uk/wp-content/uploads/2015/08/tsb_ifm_highvaluem anufacturingt12_009_final.pdf. Accessed 18 Apr 2016

20. EPSRC (2013) Distributed manufacturing, engineering and physical sciences research council. Available at https://www.epsrc.ac. uk/skills/students/centres/2013cdtexercise/priorityareas/distm anu/. Accessed 18 Apr 2016

21. Pearson H, Noble G, Hawkins J (2013) Re-distributed manufacturing workshop report. Workshop report. EPSRC. Available at https://www.epsrc.ac.uk/newsevents/pubs/re-distributed-manuf acturing-workshop-report/. Accessed 18 Apr 2016

22. Wohlers T, Caffery T (2015) Wohlers report 2015: additive manufacturing and $3 \mathrm{D}$ printing state of the industry: annual worldwide progress report. Wholers Associates Inc, Fort Collins

23. Holweg M (2015) 'The limits of 3D printing', Harvard Business Review, 23 June. Available at https://hbr.org/2015/06/the-limit s-of-3d-printing. Accessed 18 Apr 2016

24. Thiesse F, Wirth M, Kemper H-G, Moisa M, Morar D, Lasi H, Piller F, Buxmann P, Mortara L, Ford S, Minshall T (2015) Economic implications of additive manufacturing and the contribution of MIS. Bus Inf Syst Eng 57(2):139-148

25. Charnley F, Theodoulidis C, Zaki M (2015) Re-distributing the future of consumer goods. Re-distributing the future of consumer goods, disruptive innovation festival, 11 November. Available at https://www.thinkdif.co/big-top-tent-sessions/re-distributing-thefuture-of-consumer-goods. Accessed 18 Apr 2016

26. Zhang Z, Joshi S (2017) Slice data representation and format for multi-material objects for additive manufacturing processes. Rapid Prototyp J 23(1):149-161

Publisher's Note Springer Nature remains neutral with regard to jurisdictional claims in published maps and institutional affiliations. 